\title{
Multicultural Learning and Experiences in Design Through the Collaborative Online International Learning (COIL) Framework
}

\author{
Abimbola O. Asojo \\ University of Minnesota \\ aasojo@umn.edu \\ Yuliya Kartoshkina \\ University of Minnesota \\ ykartosh@umn.edu \\ Dolapo Amole \\ Obafemi Awolowo University \\ dolapoamole@gmail.com \\ Babatunde Jaiyeoba \\ Obafemi Awolowo University \\ ebjaiye@,oauife.edu.ng
}

\begin{abstract}
One of the requirements for interior design students by the Council for Interior Design Accreditation is to be "prepared to work in a variety of contexts as well as across geographic, political, social, environmental, cultural, and economic conditions." To belp with this preparation, faculty partners from two institutions - the University of Minnesota Interior Design program and the Obafemi Awolowo University Architecture program in Nigeria — created unique learning experiences for their students using the collaborative online international learning (COIL) framework. The main goal of this teaching methodology is to develop students' cross-cultural competence by linking university classes in different countries. Two COIL projects were chosen to help students practice solving design problems while responding to specific sociocultural contexts. Students from both countries benefited from this learning experience. Findings from students' reflections after the experiences indicated deeper intercultural sensitivity in their design solutions and appreciation of technology and collaborative learning. Overall the COIL framework strengthened the integration of multicultural learning experiences in both settings.
\end{abstract}

Keywords: collaborative online international learning (COIL), interior design, intercultural pedagogy, intercultural learning, culture, diversity

\section{Introduction}

Students in all disciplines need to be prepared to work and live with people from diverse cultural backgrounds, as the world is becoming more interconnected. This trend toward interconnectedness puts the responsibility on universities to help students develop the intercultural skills needed to be successful in a global economy and attain jobs after graduation. One such foundational skill is the development of intercultural sensitivity. According to Bennett (1993), who developed the developmental model of intercultural sensitivity, there are several stages to expanding one's sensitivity to other cultures. Bennett emphasized that this journey is developmental and with experience, awareness, and practice, a person can move from cultural ethnocentrism, seeing one's culture as "central to reality," to cultural ethnorelativism, where culture is seen as "relative to context." Overall, 
intercultural sensitivity involves becoming conscious of differences among cultures and being able to respect and accept those differences (Chen \& Starosta, 2000).

In the United States, study abroad experience has been historically the most common way universities and colleges help students develop intercultural sensitivity. However, not all students can afford such an experience or are able to include it their course of study. According to the most recent Institute of International Education (2017) Open Doors report, only 16\% of U.S. students seeking a bachelor's degree were able to study abroad during the 2016-2017 academic year. Therefore, local classrooms where the majority of students receive their education becomes an environment where intercultural skills need to be fostered.

In design curricula, the pedagogical strategy of teaching students about different cultures has been accomplished predominantly through history courses where students are exposed to different historical styles around the world. The problem is that within the context of a history course, students do not have the opportunity to practice solving design problems in a cross-cultural context. At the same time, the population of the United States is becoming more diverse and multicultural, with a recent U.S. census report indicating that $39.3 \%$ of the U.S. population is non-White (United States Census Bureau, 2019). It is thus crucial for future designers to be aware of different cultural contexts. They will need to be able to conduct culturally sensitive research and engage in projects that take into consideration cultural nuances. The accreditation board for interior design education in the United States recognizes the importance of integrating cultural diversity and global issues in design education. The Council for Interior Design Accreditation (2018) dedicates one of its 16 standards (Standard 4) to global context: It requires that interior design graduates be "prepared to work in a variety of contexts as well as across geographic, political, social, environmental, cultural, and economic conditions." (p. 16). Thus, design faculty need to find ways to include elements of intercultural and global learning in their courses and especially to develop the foundational skills of intercultural sensitivity.

One pedagogical strategy for approaching this methodological gap is to create international partnerships with universities abroad and to help students collaborate with their peers abroad virtually. This approach is also known as collaborative online international learning (COIL). According to the State University of New York (SUNY) Center for Collaborative Online International Learning, one of the leading international organizations focused on the emerging field of globally networked learning, COIL is designed to cultivate "cross-cultural student competence through development of multicultural learning environments that link university or college classes in different countries." (The SUNY Center for Collaborative Online International Learning, 2017). In the COIL framework, experiential cross-cultural student learning is fostered in co-created online environments that link college classes in different countries using the three main components that are necessary for an effective COIL experience: pedagogy, technology, and cross-cultural learning (The SUNY Center for Collaborative Online International Learning, 2017).

"COILing" a course is an opportunity to grow for both students and instructors that can enhance the course content and provide experiences similar to study abroad in fostering intercultural learning (The SUNY Center for Collaborative Online International Learning, 2017). Lo, Johnson, and Tenorio (2011), in their study about student learning in an online environment, showed that "having students participate in online assignments can promote student satisfaction and foster critical thinking and deep learning” (p. 1). Similarly, Bai, Larimer, and Riner (2016) highlighted bringing faculty from international settings, integration with the host university, and student reflection as important aspects of strong cross-cultural pedagogy. Both studies reinforce the importance of the three main COIL components, pedagogy, technology, and cross-cultural learning.

In the current paper we describe how a design faculty at the University of Minnesota developed several COIL projects for students (Figure 1). We present an overview of the partnership 
with Nigerian colleagues at Obafemi Awolowo University, the COIL assignments, and findings about student learning based on their feedback and reflections. Future recommendations and adaptations for other courses and disciplines are also discussed.

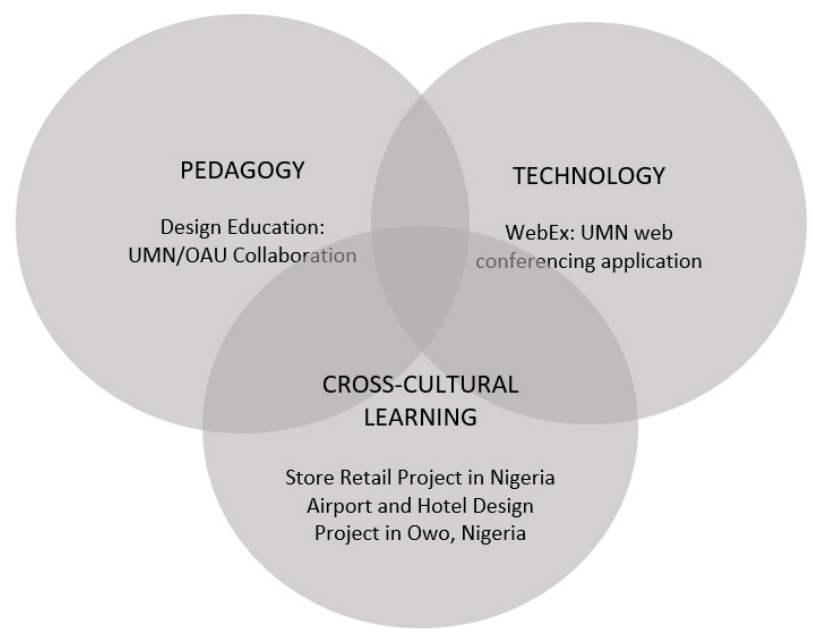

Figure 1. The three main components of collaborative online international learningpedagogy, technology, and cross-cultural learning-and their interdependence. The University of Minnesota (UMN) and Obafemi Awolowo University (OAU) in Nigeria collaborated on two projects using the UMN Web conferencing application WebEx.

\section{COILing a Design Course}

The College of Design at the University of Minnesota consists of three academic units, (1) the School of Architecture, (2) the Department of Design, Housing, and Apparel, and (3) the Department of Landscape Architecture, with about 1,600 students. The Interior Design undergraduate program in the Department of Design, Housing, and Apparel has about 140 students. The vision of the Interior Design program at the University of Minnesota is to:

Develop globally competent interior design practitioners and scholars who excel in identifying and solving interior environment problems from an evidence-based, human-centered approach by applying knowledge, infusing creativity, and valuing the person and the environment through an interdisciplinary design process.... Undergraduate students learn how to be professional interior designers who design in ways that protect people's health and safety and improve human well-being. (University of Minnesota Interior Design Program, 2019)

To help students at the University of Minnesota develop global competence and provide them with real-life opportunities to practice solving design problems in cross-cultural environments, Asojo created COIL projects in a lighting design course. Thus, Asojo initiated the collaboration.

To COIL a course, faculty members need to think about many factors involved in setting up such a collaboration. According to the SUNY Center for Collaborative Online International Learning (2019), some of these important factors are (1) determining content and institutional resources, (2) finding a partner, and (3) agreeing on pedagogical components and logistics of teaching a course together. 


\section{Determining Content and Institutional Resources}

To go through this stage, Asojo (University of Minnesota faculty member) had to answer three questions about (1) the qualities that make a course a good candidate for COIL, (2) readiness to teach in a technologically enhanced way, and (3) availability of institutional support (The SUNY Center for Collaborative Online International Learning, 2017). Two design projects, "The Store Retail Project in Nigeria" and "The Hotel Design Project in Owo, Nigeria," in Asojo's lighting design course were good candidates for COIL because the content and student learning could be enhanced by collaborating with peers in the geographical locations of the design projects. Both projects offered the opportunity to provide students cross-cultural experiences. In terms of technology, Asojo was very comfortable with Web conferencing applications, and the student drawings in the course involved digital representation with computer software applications. Institutional support was available through the University of Minnesota's Global Programs and Strategy Alliance Internationalizing the Curriculum and Campus initiative. Asojo received funding prior to the COIL experience to travel and visit the Nigerian faculty in summer 2016 at Obafemi Awolowo University and funding to bring the Nigerian faculty (Dolapo Amole and Babatunde Jaiyeoba) to visit Minnesota in fall 2016.

\section{Establishing the Partnership}

Establishing the partnership is another critical factor in creating an effective COIL project, as "having the right partner can literally make or break your COIL enhanced course" (The SUNY Center for Collaborative Online International Learning, 2019, p. 8). One way to establish partnerships is to look into already existing professional relationships with faculty abroad. In the present example, University of Minnesota faculty (Asojo) had research collaborations with Nigerian faculty from the Obafemi Awolowo University Architecture Department (Amole and Jaiyeoba). This existing relationship offered a great opportunity to capitalize on this partnership for the lighting design course. During their fall 2016 visit to the University of Minnesota, the Nigerian faculty were able to attend a course that was intended for COILing, to co-lecture on Nigerian culture for this course, and to provide U.S. students with feedback on their design projects in class. This experience was very beneficial in the follow-up discussions about organizing pedagogical and logistical aspects of the collaboration.

In-person discussions between faculty from Minnesota and Nigeria were very valuable in deciding on the details of how the partnership would continue virtually, what projects would work best, and what platform to use for online communication. For example, the partners agreed that Nigerian architecture students would provide feedback to the U.S. students twice during the project. Also, besides discussing the pedagogical aspects of the course, the partners needed to take into account the 6-h time difference between the United States and Nigeria, the cost of Internet access in Nigeria, and the platform for their synchronous meetings. WebEx, a University of Minnesota platform, was chosen because it offered the opportunity to Web conference, share screens for visual presentation, and record presentations. Thus, the existing research partnership, Nigerian faculty visiting the Minnesota campus to experience the course and having in-person conversations about the details of collaboration, and follow-up discussions online and by phone all contributed to establishing an effective partnership.

\section{Developing Design Projects}

To provide students with an opportunity to practice solving design problems in cross-cultural environments, University of Minnesota faculty chose the lighting design course that is usually offered 
to third-year design students. An average of 30 students from interior design, architecture, and other college majors enroll in this course every fall semester. The main goal of the course is to introduce lighting as a dynamic design element impacting interior space. Assignments and design projects emphasize the integration of lighting with interior and architectural elements. Nigerian faculty selected several graduate architecture students in their program who had taken an interior design elective.

Two design projects, "The Store Retail Project in Nigeria" and "The Hotel Design Project in Nigeria," were created for the lighting design course. Both projects lasted no longer than 6 weeks, with the class meeting twice a week. This gave faculty enough time to help students develop the foundational knowledge about Nigerian culture and architecture, and the students enough time to conduct their own research related to their project, to receive feedback from Nigerian students and faculty, and to refine their work according to the feedback.

The first project, "The Store Retail Project in Nigeria," was assigned to students in fall 2016 and 2017. The goal for students was to design the lighting and display space for a contemporary brandname store in an international airport in Lagos City, Abuja Federal Capital Territory, or Port Harcourt City in Nigeria. Students were allowed to choose their brand and location from a predetermined list. Students were required to reflect Nigerian culture in their design proposals in addition to emphasizing different layers of lighting in the space. The second project, "The Hotel Design Project in Nigeria," was assigned in fall 2018. The goal for student teams was to design the lighting and interiors for a hotel in Owo, Ondo State in Nigeria, for a client who was a retired elderly female college professor. Students were required to reflect Nigerian culture and Western influences in their design proposals in addition to emphasizing different layers of lighting in the space.

The first 2 weeks of each project were dedicated to developing students' knowledge of the culture and architecture of Nigeria. For example, on the first day the students were introduced to the project requirements, given a lecture on Nigerian architecture, and introduced to Asojo's (2013) cultural framework for design problem solving focused on the following five themes: juxtaposition of traditional and contemporary culture; social dynamics; elements and principles of design; visual and performance arts; and sustainability (Figure 2). The lecture on Nigerian architecture was jointly presented by University of Minnesota faculty and faculty from Obafemi Awolowo University. It focused on introducing students to Nigerian people, history, culture, geography, art and aesthetics, and traditional and contemporary architecture. For the next two classes, students were asked to read three articles on Nigerian architecture and work on their research, design concept, conceptual sketches, and lighting design ideas. The next two classes were dedicated to students developing their concept and schematic design and presenting them for feedback: face-to-face to visiting Nigerian faculty in 2016 and via Web conferencing to Nigerian faculty and students in 2016, 2017 and 2018. Students had about 2 weeks to refine their work based on feedback and additional desk critiques. During the last week of the class students made their final presentation via Web conferencing to Nigerian faculty and students (Figures 3, 4, and 5). At the end of the experience students from both Minnesota and Nigeria filled out a questionnaire about their experience. 


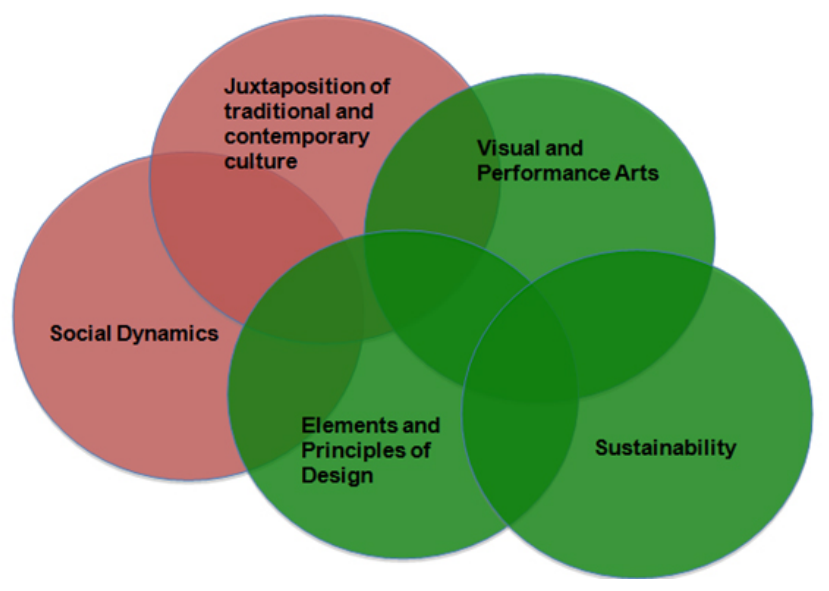

Figure 2. Five themes of Asojo's (2013) cultural framework for design problem solving. The juxtaposition of traditional and contemporary culture is an abstract theme, dealing with indigenous influences and the importance of interpreting them in design solutions in nonliteral and non-stereotypical ways. Social dynamics, the second abstract theme focuses on ethnicity, cultural diversity, philosophy, religion, government and iconic figures in the cultures, community, social interaction and family. The visual and performing arts, a concrete theme includes artifacts, the arts and crafts. The elements and principles of design, a second concrete theme, characterizes the seven elements of design (point, line, form, shape, space, texture and color) and seven principles of design (balance-symmetrical or non-symmetrical—rhythm, emphasis, proportion, scale, unity/harmony, and movement). Sustainability, a third concrete theme, characterizes the importance of nature, the use of local materials, and climatic considerations.

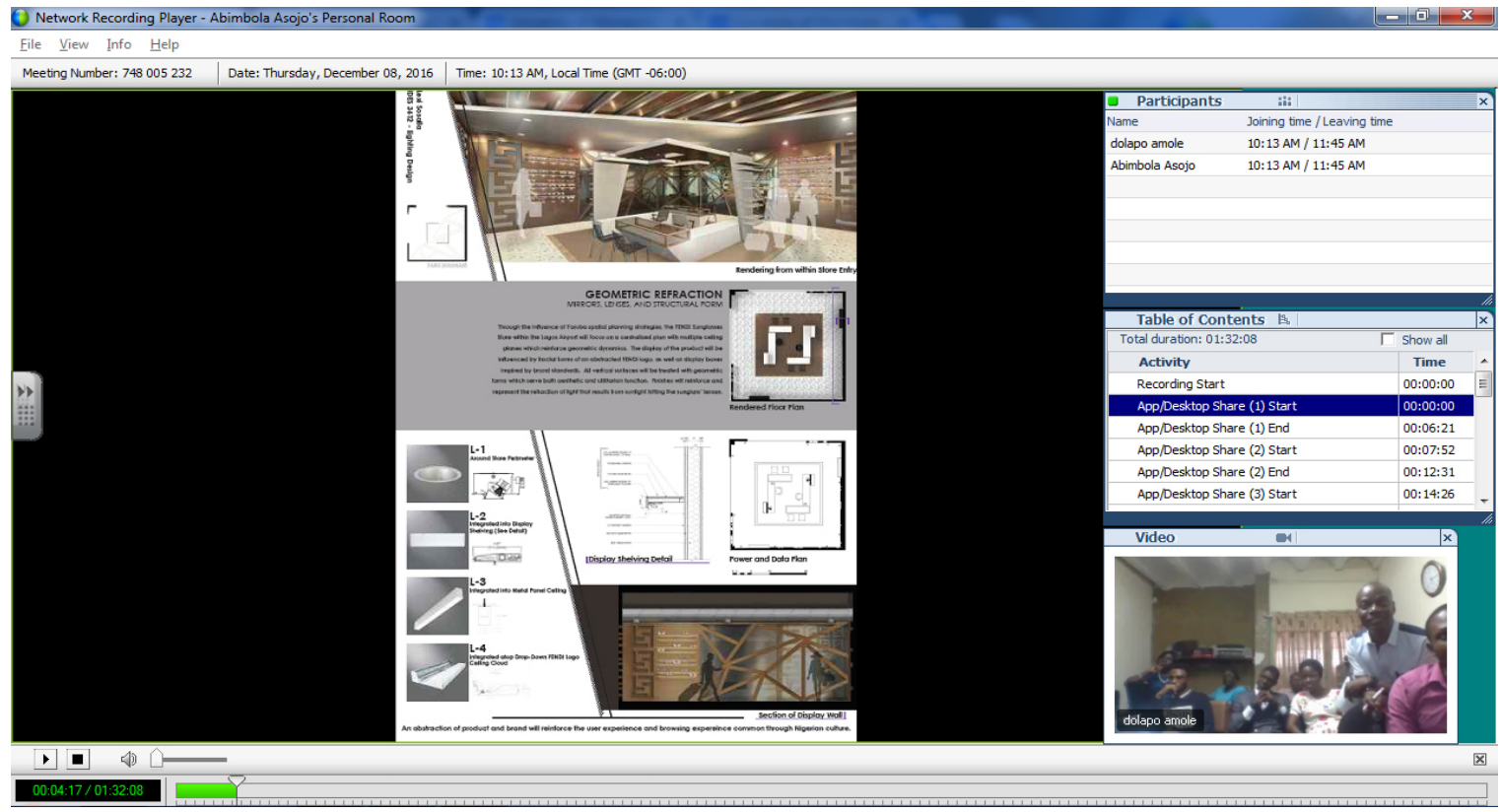

Figure 3. The "Store Retail Project in Nigeria" Web conferencing presentation, fall 2016. 


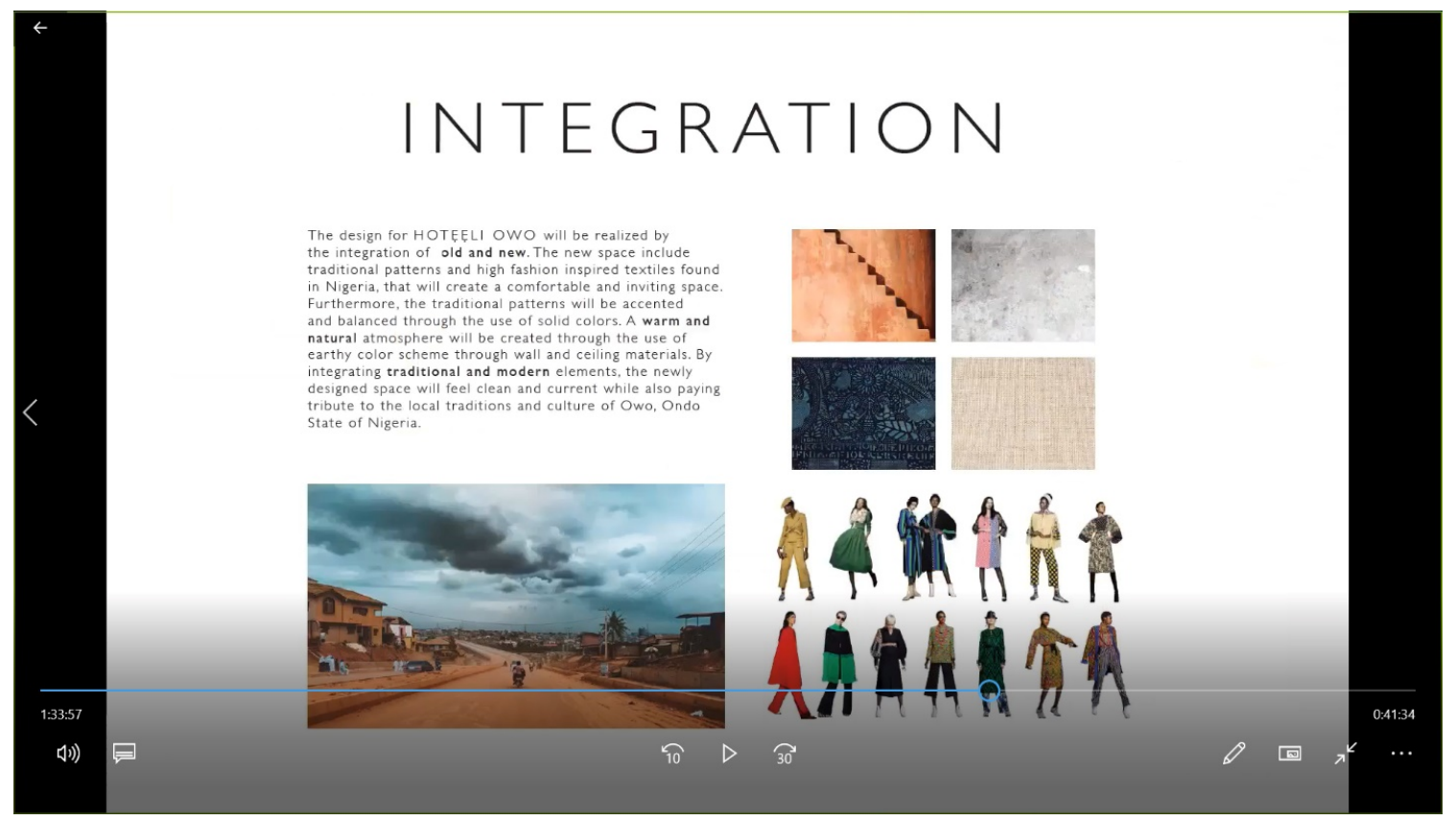

Figure 4. The "Hotel Design Project in Owo, Nigeria" Web conferencing presentation, fall 2018.

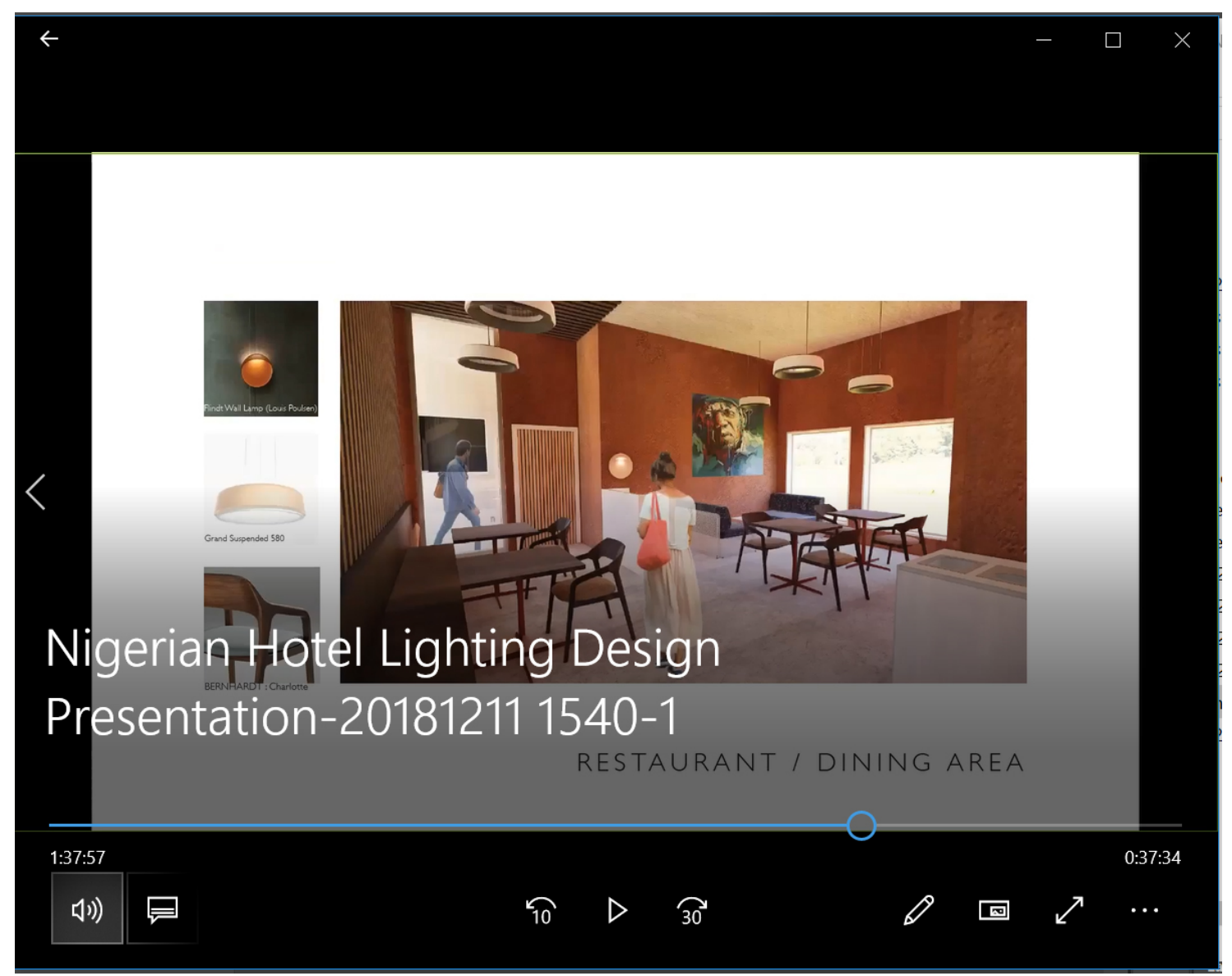

Figure 5. The "Hotel Design Project in Owo, Nigeria" Web conferencing presentation, fall 2018. 


\section{Student Learning}

Faculty at both universities were interested in what students were learning through this COILed project, in both Minnesota and Nigeria. Thus, at the end of each semester, all students were given a short online survey to reflect on their learning. The questions were the following:

(i) How did the Juxtaposition of Traditional and Contemporary Culture theme impact your design?

(ii) How did the Social Dynamics theme impact your design solution?

(iii) How did the Visual and Performance Arts theme impact your design solution?

(iv) How did the Elements and Principles of Design impact your design solution?

(v) How did Sustainability impact your design solution?

(vi) What was/were the most important thing(s) you learned in this course in relation to global/international/intercultural issues?

(vii) What in this course most helped you learn about global/international/intercultural issues?

A thematic analysis was conducted on the qualitative data collected from the open-ended questions by the authors. Through a process of continual comparison, grouping, and categorizing of the data (Miles \& Huberman, 1994; Stake, 2006; Strauss \& Corbin, 1998), the following two themes emerged: cultural sensitivity in design and importance of collaboration and technology.

\section{Cultural Sensitivity in Design}

Responses from both U.S. and Nigerian students indicated that they became much more aware and sensitive when designing projects for potential clients and providing feedback on each other's work. U.S. students seemed to have many realizations regarding why and how to be more culturally sensitive. As for why, they realized that it is very important to conduct research about a culture you are designing for, to avoid assuming what is needed and stereotyping people. One student reflected:

I had to do a lot of research on finding out the traditions and culture of a specific country. I did this so that my design would not offend that group of people and also to avoid stereotypes.

Another student realized that to be a good designer, it is important to conduct culturally sensitive research:

I learned that research is crucial, we have no choice as designers but to accept that there are many cultures we know little or nothing about, but also that we must educate ourselves in order to do design effectively in those places.

As for how, U.S. students in this class learned to incorporate different elements of Nigerian culture into their designs. For example, one student commented: "I used Nigerian contemporary art as my inspiration, so it informed my design through color and curving lines." Another student shared: "I was highly inspired by traditional Nigerian art and textiles. This translated into my design." Some students commented on how they paid close attention to the environment and integrated natural light in their project. One student shared: 
Local wood and stone tile would be used, and there is an abundance of natural light so general ambient lighting could be kept at a minimum during the day. I used harder materials to keep them from rotting in [the] often humid climate, and to prevent replacements from being needed frequently.

For the Nigerian students, the COIL collaboration allowed them to practice providing feedback (known as "crits" in design) in a different cultural context. This was an instructive learning method for them. They learned from the designs of the Minnesota students (who were students like themselves) what the most important issues were in the process of design and especially in the translation of design ideas to physical form. It appeared that providing a crit was an easier way to learn because they could see and appreciate some of the problems they also could have had in the design process. Nigerian students also learned to be culturally sensitive in their role as crit providers. Before the interactive online sessions with the Minnesota students, they were briefed on the cultural differences in critiquing and communication with other cultures. This was apparent in the way they critiqued the projects. The students learned to identify the positive issues in the projects first before identifying aspects that could be improved upon. In this way they learned to be culturally sensitive in their communication. One of the students at the end remarked that "I think I like this way of critiquing... and I had to be careful not to critique like my tutors did..."

The Nigerian faculty observed that the Nigerian students benefited from the University of Minnesota students' reinterpretation of cultural elements that are part of their everyday lives but sometimes unappreciated in their design solutions. These same unappreciated elements yielded design concepts for the University of Minnesota students' design projects. For students at both University of Minnesota and Obafemi Awolowo University, their design concept vocabularies were enriched through the process of deriving ideas from Nigerian culture. The cultural ideas that emanated from the diverse ethnic groups in the different regions of Nigeria in which the projects are located enhanced all students' learning experiences. For example, the Yorubas of Western Nigeria and the Binis of the Midwestern region provided conceptual ideas for the student designs located in Lagos and Owo. The way of life of the Gwaris, who are the original inhabitants of Abuja, the Hausa/Fulani, and the Tiv, Nupe, and other ethnic groups in the middle belt of Nigeria were displayed in the students' designs located in Abuja. The Port Harcourt location brought to the forefront the culture of the Ijaw, Ikwere, Ogoni, and other diverse cultures of the Niger Delta region of Nigeria and the dominance of oil as the mainstay of Nigeria's economy. These explorations and interpretations reinforced the impact of the social dynamics theme from the cultural framework for design problem solving (Asojo, 2013) on students' design solutions. Furthermore, the design concepts developed from the different cultures of the Nigerian people allowed students from both universities to deconstruct elements and principles of design through a culturally sensitive inclusive lens. Cultural concepts that emanated from art, sculpture, textile design, dance, hairstyles, and language reinforced the importance of the visual and performance arts theme in the students' design solutions.

Overall, students in the United States and Nigeria indicated development of cultural sensitivity. They showed personal growth in respect and recognition that cultural differences exist, as well as an ability to adapt their designs to Nigerian values. According to Bennett's (1993) model of intercultural sensitivity, students started to reveal ethnorelativist features, such as acceptance and adaptation of cultural differences. Ethnorelativism involves viewing difference not as a threat but as a challenge as well as a desire to develop new categories for understanding rather than depending on the old ones (Bennett, 1993). The COILing experience led students who took this course and learned about Nigerian culture to develop both an awareness of different cultural practices and the ability to incorporate their new knowledge into their design projects. COIL is therefore an important way to prepare future interior designers who will have clients from diverse cultural backgrounds. As Nelson 
and Stolterman (2003) emphasized, good designers need to be able to find "the most appropriate response to the unique requirements of the design situation" (p. 137). And one of these unique requirements will be the need to be culturally sensitive.

\section{Importance of Collaboration and Technology}

Many U.S. students, especially during the first lighting project when Nigerian faculty visited their class, responded very favorably to having international visitors in their classroom. One student reflected:

[I enjoyed] having people come and talk to us who are from another country (even though this may not be attainable for all projects) [and hearing] them talk from their point of view and what they would like to see us accomplish.

Students also enjoyed having feedback from their Nigerian visitors. One student shared that "having them see our final projects was fun and their feedback helped a lot!"

Both U.S. and Nigerian students said how much they valued the technology that allowed for this intercultural learning to happen. For example, one student commented "that it's possible with technology to do research and execute projects in parts of the world without having to be physically present."

Students also really enjoyed their interactions with each other. One student commented: "The opportunity to interact with and learn from students of similar professional background on an international level is quite amazing."

Both collaboration and technology are important parts in establishing successful COIL projects. Collaboration provides the opportunity to bring in multiple perspectives and partners who understand the culture to enrich the design problem-solving experiences. This theme coincides with students' reflections from other COILed courses mentioned in the SUNY 2013 report on COIL Institute case studies (SUNY COIL Center, 2013). In this report, positive comments were usually about students' appreciation for having had access to different points of view; they also indicated a high level of awareness of "self" and "other." This report also mentioned students' enthusiasm as one of the positive highlights of the experience. Students' reflections on the lighting design course universally expressed an abundance of enthusiasm from being taught by both U.S. and Nigerian faculty as well as receiving feedback from their international peers. In addition, having students learn from Nigerian faculty and students about the culture and architecture in Nigeria and receive feedback about their proposals provides the kind of collaborative relationship design students need to develop in reallife design problem solving.

As for technology, it was instrumental in achieving this COIL experience. It provided an opportunity to bring a Nigerian experience into the design studio virtually. It was very surprising to see that students really appreciated the technology, as usually in COIL courses technology is reported as one of the points of frustration (The SUNY Center for Collaborative Online International Learning, 2017). In the SUNY 2013 report (SUNY COIL Center, 2013), many instructors and students in COIL courses commented on several challenging aspects of technology - agreeing on the technology to use, learning how to use the technology, and overcoming frustration when the technology did not work. At the same time, some students in that report mentioned that even though they "hated" technology, they were grateful that it allowed them to learn from people in another country. Students in the lighting design course wrote only about positive aspects of the technology. This does not mean that there were no challenges at all, but if technology works and all the aspects of organization have been taken care of, it becomes a very positive experience for students in both countries. 


\section{Conclusion}

The COIL experience embedded in the lighting design course provides several insights for design educators. This experience gave students the opportunity to start developing cross-cultural sensitivity, appreciation for technology, and collaborative international learning and teaching. The U.S. and Nigerian students became more conscious of cultural perspectives when thinking about design projects either as designers or when providing crits. The three main components of COILpedagogy, technology, and cross-cultural learning-strengthened the integration of multicultural perspectives in this course.

The COIL experience also contributed to strengthening of the partnership between two universities and among professors. This has been a unique learning experience not only for students but also for the faculty. The Nigerian faculty observed that their students who were part of the crit process improved in knowledge about culturally sensitive design. Many cultural aspects that the students took for granted were explored by the University of Minnesota interior design students. Therefore, the Nigerian faculty decided to enhance the predesign briefing process of design studio projects in their architecture department with more cultural issues. This became a subject of discussion in subsequent departmental studio project proposal review sessions. Furthermore, the Nigerian faculty now appreciates the need for international learning and teaching exposure through continuing this COIL experience, and for international student and staff exchange. COIL is seen as a viable means of international exchange of learning and knowledge generation while other modalities for international exchanges are being worked on.

This collaboration demonstrated that it is possible to teach students about other cultures without physically taking them abroad. By taking time to discuss the details of the collaborative assignments and carefully planning the structure of the interactions, faculty partners from the United States and Nigeria were able to create an enriching teaching environment where students learned to practice culturally sensitive interior design. Having had such a fruitful partnership, the authors would like to encourage other faculty in all disciplines to consider developing unique partnerships with different universities abroad and developing assignments that can be COILed. There is no one recipe to make such a course successful in enhancing students' intercultural learning - it all depends on what partners in different universities are willing to try. The authors would like to emphasize that the COIL teaching experience is definitely worth embedding in any course but it requires careful and thoughtful planning from both partners. Overall, COIL can be one of the best tools for bridging the gaps between different parts of the world and improving understanding of cultural differences, developing cultural sensitivity, and ensuring cultural transmission and exchange.

\section{References}

Asojo, A. O. (2013). Instructional strategies for teaching cross-cultural design: A pedagogical example using Nigerian and South African spatial forms. International Journal of Architectural Research, 7, 76-91.

Bai, J., Larimer, S., \& Riner, M. (2016). Cross-cultural pedagogy: Practical strategies for a successful interprofessional study abroad course. Journal of the Scholarship of Teaching and Learning, 16, 7281.

Bennett, M. J. (1993). Towards ethnorelativism: A developmental model of intercultural sensitivity. In R. M. Paige (Ed.), Education for the intercultural experience (pp. 21-71). Yarmouth, ME: Intercultural Press.

Chen, G. M., \& Starosta, W. J. (2000). The development and validation of the intercultural sensitivity scale. Human Communication, 3, 1-15. 
Council for Interior Design Accreditation. (2018). Council for Interior Design Accreditation: Professional standards. Grand Rapids, MI: Author. Retrieved from https://accredit-id.org/wpcontent/uploads/2019/02/Professional-Standards-2018.pdf

Institute of International Education. (2017). 2018 fast facts: Open doors report on U.S. students studying abroad [Fact sheet]. Retrieved from https://www.iie.org/Research-and-Insights/OpenDoors/Fact-Sheets-and-Infographics/Fast-Facts

Lo, C., Johnson, E., \& Tenorio, K. (2011). Promoting student learning by having college students participate in an online environment. Journal of the Scholarship of Teaching and Learning, 11(2), 115.

Miles, M. B., \& Huberman, A. M. (1994). Qualitative data analysis: An expanded sourcebook. Newbury Park, CA: Sage Publications.

Nelson, H. G., \& Stolterman, E. (2003). The design way: Intentional change in an unpredictable world. Englewood Cliffs, NJ: Educational Technology Publications.

Stake, R. E. (2006). Multiple case study analysis. New York, NY: Guilford.

Strauss, A., \& Corbin, J. (1998). Basics of qualitative research: Techniques and procedures for developing grounded theory (2nd ed.). Thousand Oaks, CA: Sage.

The SUNY Center for Collaborative Online International Learning. (2017). About COIL. Retrieved January 21, 2019, from http://coil.suny.edu/page/about-coil-0

The SUNY Center for Collaborative Online International Learning. (2019). Guide for collaborative online international learning course development. Retrieved from http://coil.suny.edu

The SUNY Center for Collaborative Online International Learning. (2013). The COIL Institute for Globally Networked Learning in the Humanities final report. Retrieved from http://coil.suny.edu/sites/default/files/case_study_report.pdf

United States Census Bureau. (2019). United States Census Bureau State \& County Quick Facts. Retrieved from https://www.census.gov/quickfacts/fact/table/US/PST045217

University of Minnesota Interior Design Program. (2019). Interior design strategic plan. Retrieved from https://interior.design.umn.edu/about/strategic.html 